\title{
Semi-Synthesis and In Vitro Anti-Cancer Evaluation of Magnolol Derivatives
}

\author{
Xiao-Long Sun ${ }^{1}$, Mei-Lin Zhu ${ }^{1}$, Yi-Qun Dai ${ }^{1}$, Hong-Mei Li ${ }^{1}$, Bo-Han Li ${ }^{1}$, Hui Ma ${ }^{1}$, Chang-Hao Zhang ${ }^{2, *}$ \\ and Cheng-Zhu $\mathrm{Wu}^{1}{ }^{1}$ * \\ 1 School of Pharmacy, Bengbu Medical College, 2600 Donghai Road, Bengbu 233030, China; \\ sunxiaolong96@foxmail.com (X.-L.S.); zlyk521@126.com (M.-L.Z.); daiyiqun25@126.com (Y.-Q.D.); \\ athongmei@bbmc.edu.cn (H.-M.L.); libohan1228@foxmail.com (B.-H.L.); mahui9513@foxmail.com (H.M.) \\ 2 Key Laboratory of Natural Medicines of the Changbai Mountain, College of Pharmacy, Yanbian University, \\ Ministry of Education, 977 Gongyuan Road, Yanji 133002, China \\ * Correspondence: zhangch@ybu.edu.cn (C.-H.Z.); wuchengzhu0611@bbmc.edu.cn (C.-Z.W.); \\ Tel.: +86-443-243-6006 (C.-H.Z.); +86-552-317-5232 (C.-Z.W.)
}

Citation: Sun, X.-L.; Zhu, M.-L.; Dai, Y.-Q.; Li, H.-M.; Li, B.-H.; Ma, H.;

Zhang, C.-H.; Wu, C.-Z.

Semi-Synthesis and In Vitro

Anti-Cancer Evaluation of Magnolol Derivatives. Molecules 2021, 26, 4302. https://doi.org/10.3390/

molecules26144302

Academic Editor: Claudio Frezza

Received: 18 June 2021

Accepted: 13 July 2021

Published: 15 July 2021

Publisher's Note: MDPI stays neutral with regard to jurisdictional claims in published maps and institutional affiliations.

\begin{abstract}
Magnolol (MAG), a biphenolic neolignan, has various biological activities including antitumor effects. In this study, 15 MAG derivatives were semi-synthesized and evaluated for their in vitro anticancer activities. From these derivatives, compound 6a exhibited the best cytotoxic activity against four human cancer cell lines, with $\mathrm{IC}_{50}$ values ranging from 20.43 to $28.27 \mu \mathrm{M}$. Wound-healing and transwell assays showed that compound 6a significantly inhibited the migration and invasion of MDA-MB-231 cells. In addition, Western blotting experiments, performed using various concentrations of $\mathbf{6 a}$, demonstrated that it downregulates the expression of HIF-1 $\alpha$, MMP-2, and MMP-9 in a concentration-dependent manner. Overall, these results suggest that substituting a benzyl group having $\mathrm{F}$ atoms substituted at the $\mathrm{C} 2$ position on MAG is a viable strategy for the structural optimization of MAG derivatives as anticancer agents.
\end{abstract}

Keywords: magnolol; semi-synthesis; cytotoxicity; migration; invasion

\section{Introduction}

Triple-negative breast cancer (TNBC) is defined by a lack of expression of the estrogen receptor, epidermal growth factor receptor-2, and progesterone receptor- 2 . TNBC shows a higher rate of distant recurrence and metastasis, as well as a poorer prognosis, than other breast cancer subtypes [1,2]. Moreover, TNBC lacks standardized treatment guidelines and effective drugs [3]. For these reasons, anti-TNBC agents with high efficiency and low toxicity are needed. In contrast to chemotherapy, natural products have many advantages, such as low toxicity and side effects, multiple targets, and reversal of cancer-drug resistance $[4,5]$.

Natural products play an important role in the research and development of new drugs [6,7]. Natural products can have many advantages over chemotherapy, such as low toxicity, low side effects, multiple targets, and reversal of resistance to cancer drugs. Magnolol (MAG, 5,5'-diallyl-2,2'-dihydroxybiphenyl), a lignan isolated mainly from Magnolia officinalis, Rehder \& E.H. Wilson ("Hou Po" in Chinese) [8], exhibits a huge range of biological activities such as anti-inflammatory [9], neuroprotective [10], antibacterial [11], antioxidant [12], and antitumor [13] effects. In addition, many recent studies have shown that MAG can inhibit the proliferation, migration, metastasis, and angiogenesis of various cancer cell lines [14-17], suggesting that MAG has potential as a lead compound for the discovery of anticancer agents.

Previous studies have shown that a series of MAG derivatives showed better cytotoxic activity than MAG itself [18-22]. These results indicated that free phenolic hydroxyl groups and hydrophobic side chains are the necessary active groups for magnolol to exert 
antitumor effects. However, in a previous study we showed that monosubstitution of a benzyl group with $\mathrm{Cl}$ atoms at the phenolic hydroxyl group of honokiol significantly improved the cytotoxic activity of honokiol against cancer cells [23]. In this study, we modified the phenolic hydroxyl of MAG to obtain a series of novel MAG derivatives and examined the cytotoxic activity of these derivatives against four human cancer cell lines, as well as their inhibition of the migration and invasion of MDA-MB-231 cells.

\section{Results and Discussion}

\subsection{Synthesis and Characterization of the Derivatives}

A series of 15 MAG derivatives were designed and synthesized using MAG as the starting material (Scheme 1.). Methyl, ethyl, benzyl, 2-fluorobenzyl, 3-fluorobenzyl, 4fluorobenzyl, 2-chlorobenzyl, 3-chlorobenzyl, and 4-chlorobenzyl were substituted on the phenol groups of MAG via the Williamson reaction to obtain monosubstituted products 1a-9a and disubstituted derivatives $\mathbf{1} \mathbf{b}-\mathbf{6} \mathbf{b}$. The chemical structures of the MAG derivatives were characterized using ${ }^{1} \mathrm{H}-\mathrm{NMR},{ }^{13} \mathrm{C}-\mathrm{NMR}$, ESI-MS, and HR-ESI-MS. (see Supplementary Materials).<smiles>[R4]C(C)Cc1cc(O)c(-c2cc(CC=C)ccc2O)cc1CC=C</smiles><smiles>[R]Oc1ccc(CC=C)cc1-c1cc(CC=C)ccc1O</smiles>

a

$$
\text { 1a-1b } \mathrm{R}=-\mathrm{CH}_{3}
$$

9a<smiles>[R]Oc1ccc(CC=C)cc1-c1cc(CC=C)ccc1O[R]</smiles>

b
$\mathrm{R}=$<smiles>CCCc1ccc(F)cc1</smiles>

$7 \mathbf{a}$

$\mathrm{R}=$<smiles>CCc1ccccc1Cl</smiles>

8a

$\mathrm{R}=$<smiles>CCCc1cccc(Cl)c1</smiles><smiles>[R]CCc1ccc(Cl)cc1</smiles>

Scheme 1. Synthetic routes for magnolol derivatives.

\subsection{In Vitro Cytotoxic Activity}

All synthesized derivatives were evaluated for their in vitro cytotoxic activity against four human cancer cell lines using the MTT assay with Taxol as a positive control. The inhibited cell growth to $50 \%$ of the control $\left(\mathrm{IC}_{50}\right)$ was determined for the compounds, and the results are summarized in Table 1. Compounds 1a-9a all exhibited cytotoxic activity against one or more types of cancer cell lines. Compounds 3a, $\mathbf{4 a}, \mathbf{5 a}$, and $\mathbf{6 a}$ had better cytotoxic activity against all four human cancer cell lines than compounds $\mathbf{2 a}$ or $\mathbf{7 a}-\mathbf{9} \mathbf{a}$, with $\mathrm{IC}_{50}$ values ranging from 20.43 to $30.21 \mu \mathrm{M}$. Compound $\mathbf{6 a}$ showed the best cytotoxic activity against the human TNBC MDA-MB-231 cell line with an $\mathrm{IC}_{50}$ value of $20.43 \mu \mathrm{M}$, which indicates 6a was approximately 2.5 times stronger than magnolol. 
Table 1. Cytotoxic activity of magnolol derivatives $\left(\mathrm{IC}_{50}, \mu \mathrm{M}, 72 \mathrm{~h}\right)$.

\begin{tabular}{|c|c|c|c|c|}
\hline \multirow{2}{*}{ Compound } & \multicolumn{4}{|c|}{ IC $_{50}$ Values $(\mu \mathrm{M})$} \\
\hline & MDA-MB-231 ${ }^{a}$ & MCF-7 ${ }^{b}$ & CNE-2Z ${ }^{\mathrm{c}}$ & SMMC-7721 ${ }^{d}$ \\
\hline $1 \mathrm{a}$ & $>50^{\mathrm{e}}$ & $34.7 \pm 0.87^{\mathrm{f}}$ & $45.87 \pm 0.51$ & $>50$ \\
\hline $1 b$ & $>50$ & $>50$ & $>50$ & $>50$ \\
\hline $2 a$ & $>50$ & $29.76 \pm 1.06$ & $47 \pm 1.29$ & $44.49 \pm 4.41$ \\
\hline $2 b$ & $>50$ & $>50$ & $>50$ & $>50$ \\
\hline $3 a$ & $22.85 \pm 2.15$ & $26.32 \pm 2.39$ & $25.85 \pm 4.47$ & $30.21 \pm 3.06$ \\
\hline $3 b$ & $>50$ & $>50$ & $>50$ & $>50$ \\
\hline $4 a$ & $26.95 \pm 1.04$ & $26.77 \pm 2.12$ & $27.2 \pm 2.31$ & $28.08 \pm 3.64$ \\
\hline $4 b$ & $>50$ & $>50$ & $>50$ & $>50$ \\
\hline $5 a$ & $24.51 \pm 0.62$ & $23.61 \pm 1.03$ & $27.81 \pm 2.74$ & $27.94 \pm 1.08$ \\
\hline $5 b$ & $>50$ & $>50$ & $>50$ & $>50$ \\
\hline $6 a$ & $20.43 \pm 2.17$ & $28.27 \pm 2.89$ & $22.35 \pm 2.55$ & $23.07 \pm 1.95$ \\
\hline $6 b$ & $>50$ & $>50$ & $36.47 \pm 4.20$ & $>50$ \\
\hline $7 a$ & $>50$ & $32.83 \pm 0.28$ & $45.06 \pm 2.69$ & $34.35 \pm 4.00$ \\
\hline $8 a$ & $48.93 \pm 4.49$ & $30.90 \pm 0.47$ & $46.64 \pm 0.69$ & $32.97 \pm 5.39$ \\
\hline $9 a$ & $>50$ & $30.65 \pm 0.98$ & $36.95 \pm 0.56$ & $32.30 \pm 1.59$ \\
\hline MAG & $54.70 \pm 0.95$ & $46.37 \pm 1.75$ & $57.52 \pm 3.22$ & $58.24 \pm 4.78$ \\
\hline Taxol & $0.69 \pm 0.06$ & $0.43 \pm 0.04$ & $1.71 \pm 0.19$ & $0.22 \pm 0.03$ \\
\hline
\end{tabular}

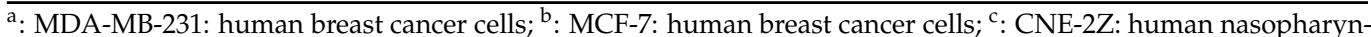
geal carcinoma cells; ${ }^{\mathrm{d}}$ : SMMC-7721: human breast cancer cells; ${ }^{\mathrm{e}}$ : No inhibitory activity at $50 \mu \mathrm{M}$; : The half maximal inhibitory concentration \pm standard deviation (SD).

The preliminary structure-activity relationship (SAR) study suggested that $O$-alkylation of the 2-OH or 2'-OH group of MAG improved cytotoxic activity against MCF-7, CNE-2Z, and SMMC-7721 cells, while both 2-OH and $2^{\prime}-\mathrm{OH}$ alkylated derivatives were inactive at $50 \mu \mathrm{M}$. Therefore, the hydroxyl group of MAG may be one of the active groups for cytotoxic activity. Moreover, the substituents on the benzyl ring had a significant influence on the cytotoxic activity of the derivatives for MDA-MB-231 cells. The activities of the F-substituted derivatives (4a, 5a, and $\mathbf{6 a}$ ) were stronger than those of the $\mathrm{Cl}$-substituted derivatives. Compound 3a, which does not bear any substitution on the benzene ring, showed good cytotoxic activity against MDA-MB-231 cells.

\subsection{Preliminary Screening of the Inhibitory Effect on MDA-MB-231 Cell Migration}

Tumor cell migration is an important event in the invasion and metastatic cascade of cancer [24]. In the preliminary screening, wound-healing assays indicated that compounds 5a, 6a, and 9a exhibited significant inhibitory effects on MDA-MB-231 cell migration at a concentration of $10 \mathrm{~mm}$ (Figure 1). As shown in Figure 2, transwell assays indicated that compounds 2a-6a, 8a, and 9a also showed potent inhibitory activities on the migration of MDA-MB-231 cells compared with MAG. Preliminary screening results showed that compound 6a had the best anti-migration activity of the MAG derivatives. Therefore, compound 6a was selected for further experiments.

\subsection{Anti-Proliferative Activity of Compound 6a in MDA-MB-231 Cells}

To understand the anticancer activity of $6 \mathrm{a}, \mathrm{MDA}-\mathrm{MB}-231$ cells were treated with increasing concentrations of the compound $(0,10,20,30,40$, and $50 \mu \mathrm{M})$ for 24,48 , and $72 \mathrm{~h}$, and cell proliferation was measured using an MTT assay. As shown in Figure 3, 6a showed significant antiproliferative activity on MDA-MB-231 cells in a time and concentrationdependent manner. When the concentration of $\mathbf{6 a}$ was increased to $50 \mu \mathrm{M}$, cell proliferation was almost completely inhibited. Therefore, 5,10 , and $20 \mu \mathrm{M}$ 6a were used in subsequent experiments. 

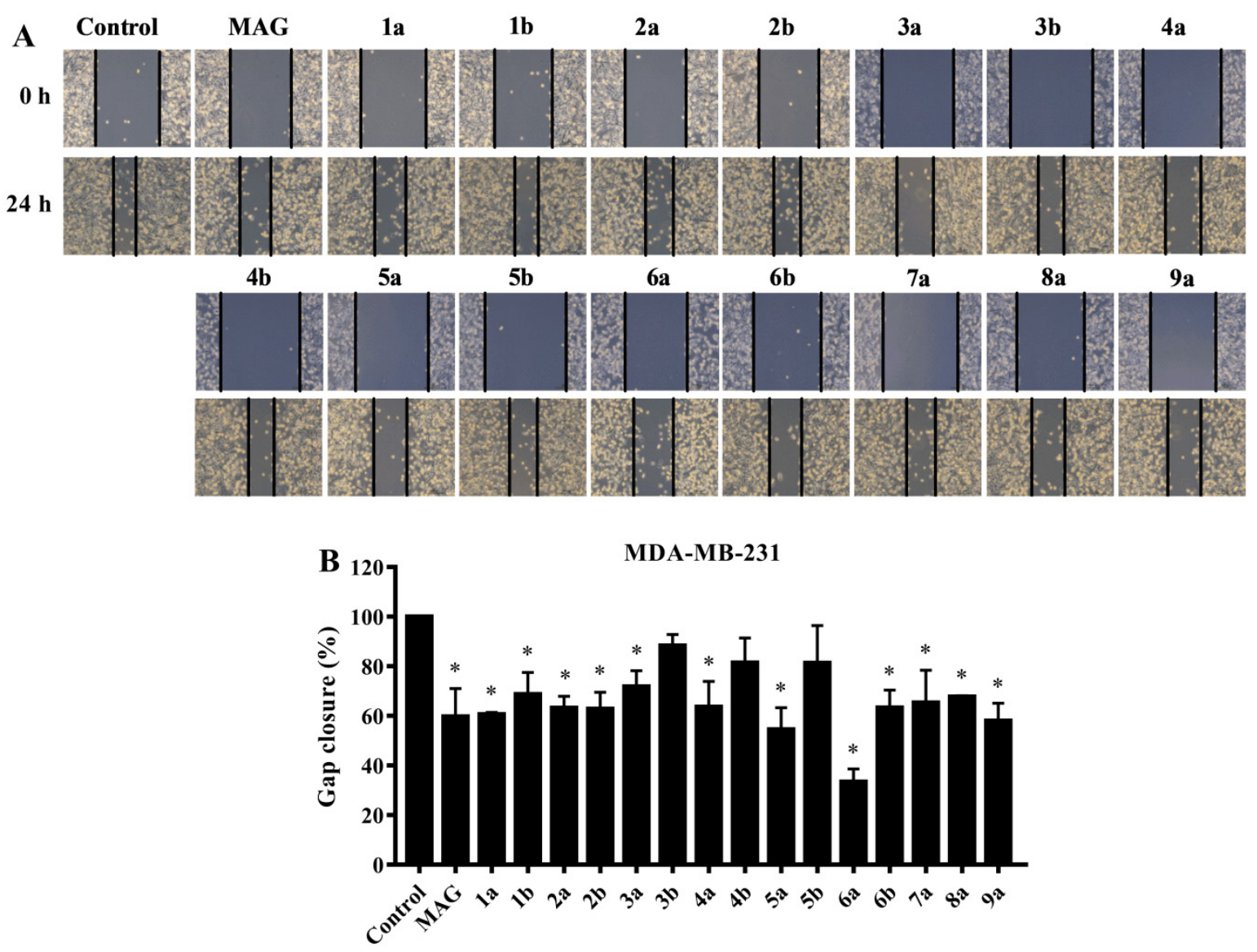

Figure 1. Preliminary screening of the effects of the MAG derivatives on the migration of MDA-MB-231 cells by a woundhealing assay. (A) MDA-MB-231 cells were seeded in a 6-well plate at a density of $6 \times 10^{5}$ cells per well and exposed to the MAG derivatives $(10 \mu \mathrm{M})$ for $24 \mathrm{~h}$. (B) Quantification analysis presented as the mean \pm standard deviation. ${ }^{*} p<0.05$ $(n=3)$.

\subsection{Suppressed Migration and Invasion of MDA-MB-231 Cells by Compound $6 \mathbf{a}$}

Tumor invasion and metastasis are the causes of poor prognosis and survival in patients with breast cancer $[25,26]$. Therefore, controlling invasion and metastasis is an important therapeutic strategy for TNBC [27]. We examined the effects of compound $\mathbf{6 a}$ on human MDA-MB-231 TNBC cells. The migration and invasion of MDA-MB-231 cells decreased as the concentration of $\mathbf{6 a}$ increased, indicating that $\mathbf{6 a}$ significantly suppressed the migration and invasion of the cells in a concentration-dependent manner (Figure 4A,B).

Hypoxia is a common feature in many solid tumors that promotes cancer invasion, metastasis, epithelial-mesenchymal transition, and angiogenesis via hypoxia inducible factor- $1 \alpha$ (HIF-1 $\alpha)$ [28-31]. This key hypoxic regulator is highly expressed in breast cancer and facilitates tumor migration and invasion through matrix metalloproteinases (MMPs) [32]. Western blotting showed that treatment with 6a significantly downregulated HIF- $1 \alpha$ and its downstream proteins MMP-2 and MMP-9 (Figure 4C). These results indicated that 6a suppressed the migration and invasion of MDA-MB-231 cells regulated by HIF- $1 \alpha$.

In our previous work, we found that the benzyl group substituted with two $\mathrm{Cl}$ atoms at phenolic hydroxyl group of honokiol, the isomer of MAG, can significantly improve the anti-proliferative activity [23]. In this study, we found that the 2-OH or 2'-OH of MAG replaced by $\mathrm{Cl}$-substituted benzyl group can also improve the anti-proliferative activity (30 $\mu \mathrm{M}$ vs. $46 \mu \mathrm{M}$ against MCF-7). Moreover, several studies have shown that selective introduction of fluorine elements into a therapeutic or diagnostic small molecule candidate can improve a number of pharmacokinetic and physicochemical properties 
such as metabolic stability and membrane permeation [33-35]. Herein, the synthesis of MAG derivatives with F-substituted benzyl group further confirmed that with greater performance in anti-proliferative, anti-migratory and anti-invasive experiments than the Cl-substituted derivatives; and the anti-proliferative activity of products with the phenolic hydroxyl group replaced by benzyl group substituted with two $\mathrm{F}$ atoms will be expected.
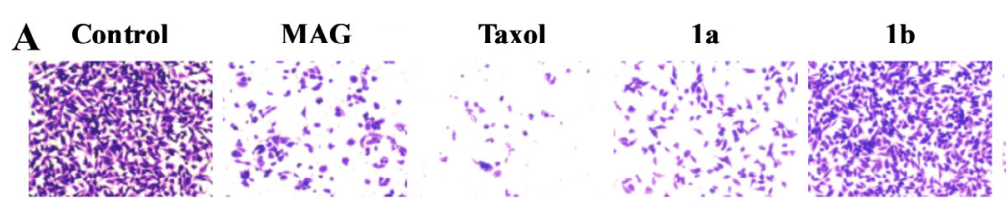

2a $\quad 2 b$

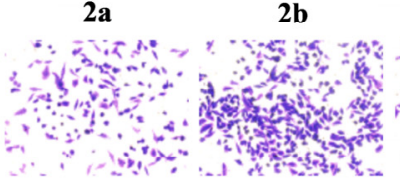

6a

6b

$7 \mathbf{a}$

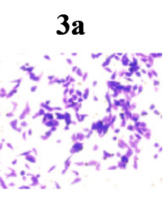

3b
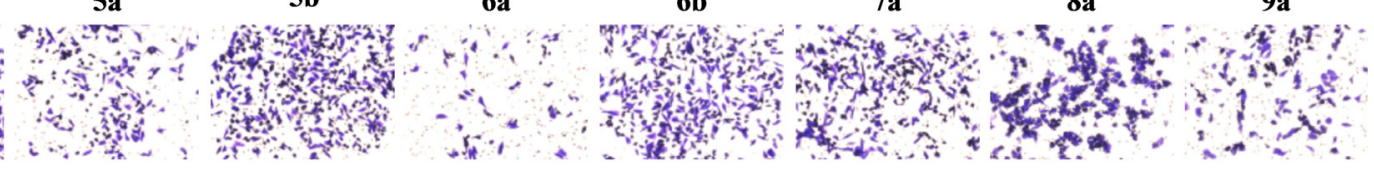

$8 \mathbf{a}$

9a

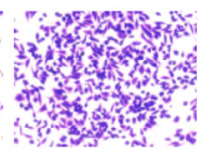

9a

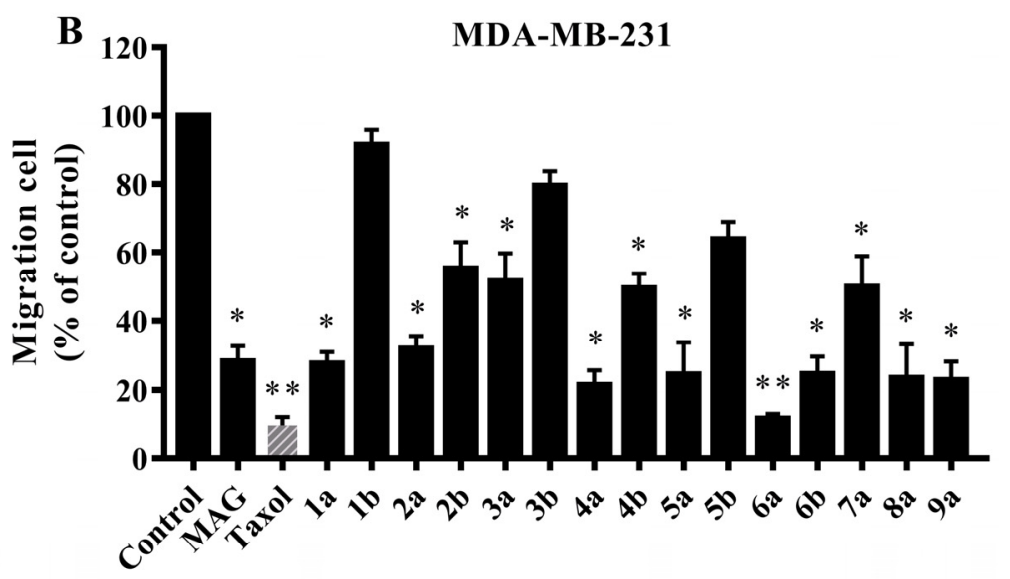

Figure 2. Preliminary screening of the effects of the MAG derivatives on the migration of MDA-MB-231 cells by a transwell assay. (A) MDA-MB-231 cells were seeded into the transwell chamber at a density of $5 \times 10^{4}$ cells per well and exposed to the MAG derivatives $(10 \mu \mathrm{M})$ for $24 \mathrm{~h}$. Taxol was used as the positive control. The cells at the lower side of the membrane were then stained using crystal violet (original magnification $200 \times$ ). (B) Quantification analysis presented as the mean \pm standard deviation. ${ }^{*} p<0.05,{ }^{* *} p<0.01(n=3)$.

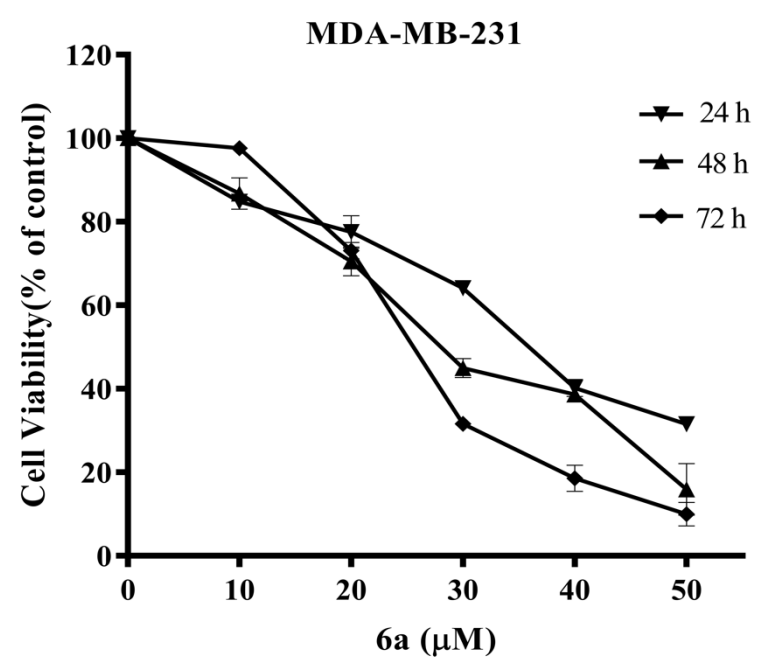

Figure 3. Anti-proliferative activity of 6a on MDA-MB-231 cells. 


\section{6a $(\mu \mathrm{M})$}

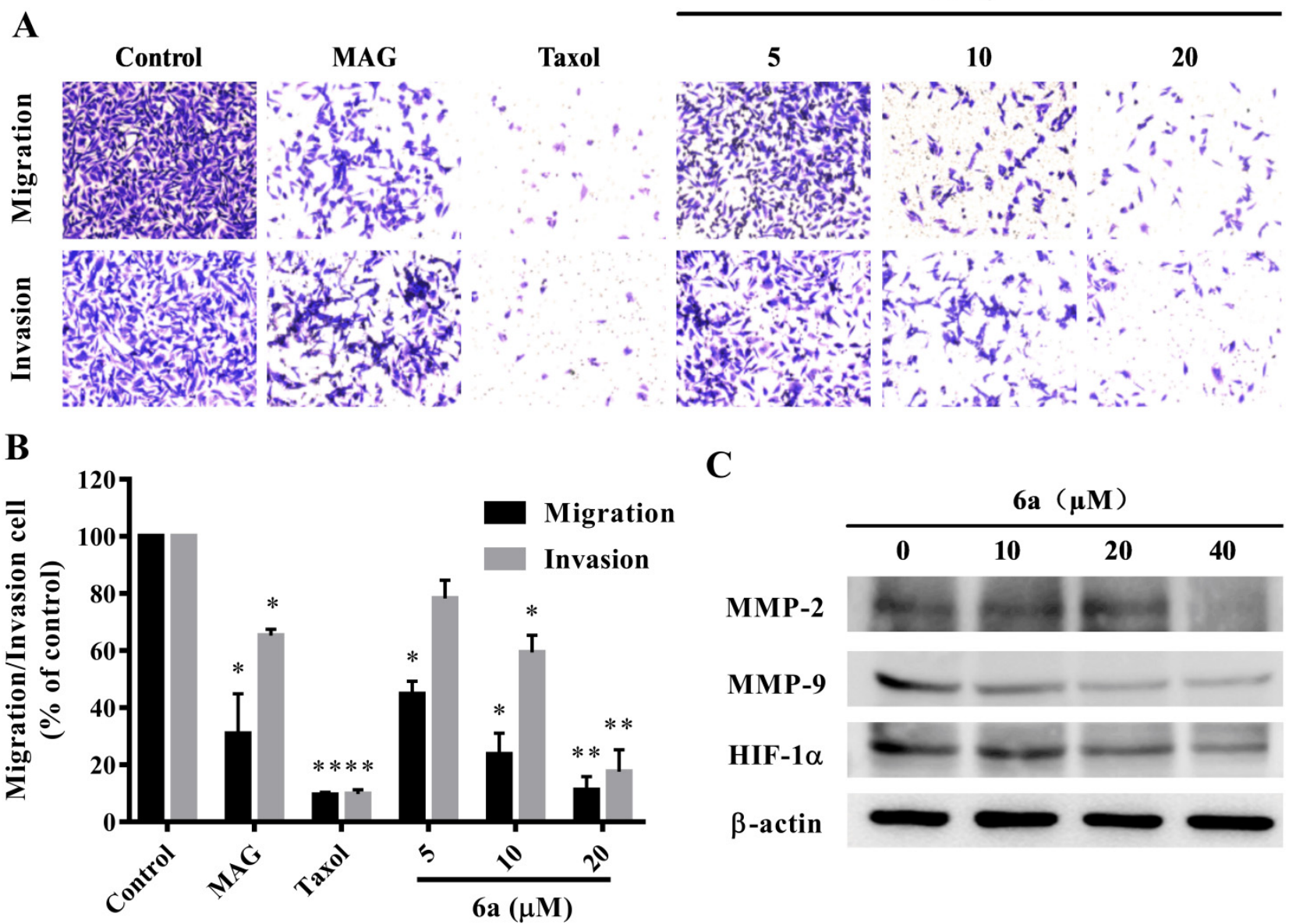

Figure 4. Effects of compound 6a on the migration and invasion of human triple-negative MDA-MB-231 breast cells by transwell assays. (A) MDA-MB-231 cells were seeded into a transwell chamber and exposed to $6 \mathbf{a}(0,5,10$, and $20 \mu \mathrm{M})$ for $24 \mathrm{~h}$ to evaluate the migration activity; MDA-MB-231 cells were also seeded into a Matrigel-coated transwell chamber and exposed to $6 \mathrm{a}(0,5,10$, and $20 \mu \mathrm{M})$ for $36 \mathrm{~h}$ to evaluate the invasion activity (original magnification $200 \times$ ). (B) Quantification analysis presented as the mean \pm standard deviation. ${ }^{* *} p<0.01,{ }^{*} p<0.05$ vs. control $(n=3)$. (C) Western blotting analyses of HIF-1 $\alpha$, MMP-2, and MMP-9 protein levels in MDA-MB-231 cells treated with various concentrations $(0,10,20$, and $40 \mu \mathrm{M})$ of $6 \mathrm{a}$ for 24 h. $\beta$-Actin was used as an internal control.

\section{Materials and Methods}

\subsection{General Information}

All reagents were commercially available and used without further purification. MAG was purchased from Xinmingtai Chemical Co., Ltd. (Wuhan, China). All reactions were monitored by thin-layer chromatography on silica gel $\mathrm{F}_{254}$ (Qindao Haiyang Chemical Co., Qindao, China). The products were purified by column chromatography (300-400 mesh silica gel, Qindao Haiyang Chemical Co., Qindao, China). All NMR spectra were recorded on a Bruker Avance II $600 \mathrm{MHz}$ instrument (Bruker, Billerica, MA, USA) using $\mathrm{CDCl}_{3}$ or DMSO- $\mathrm{d}_{6}$ as the solvent with TMS as the internal standard. Chemical shifts $(\delta)$ were reported in parts per million (ppm) and the coupling constants (J) were given in Hertz. High-resolution electrospray ionization mass spectrometry (HR-ESI-MS) spectra were recorded on a Thermo Scientific LTQ Orbitrap XL mass spectrometer (Bruker, Bremerhaven, Germany) with electrospray ionization. Taxol was purchased from Shanghai yuanye BioTechnology Co., Ltd. (Shanghai, China, batch numbers: H15F10X80839). Anti-HIF-1 $\alpha$ antibodies were purchased from Abcam (Cambridge, UK, batch numbers: GR244245-51). Anti-MMP-9 and MMP-2 antibodies were purchased from Proteintech Group (Chicago, IL, USA, batch numbers of MMP-9: 00074416; batch numbers of MMP-2: 00066968). 


\subsection{General Procedure for the Preparation of $\mathbf{1 a}-\mathbf{9 a}$ and $\mathbf{1} \mathbf{b}-\mathbf{6} \mathbf{b}$}

MAG (80 mg, $0.3 \mathrm{mM}$ ) was dissolved in $N, N$-dimethylformamide (DMF, $3 \mathrm{~mL}$ ). Sodium carbonate solution $(10 \%, 2 \mathrm{~mL})$ and the desired halohydrocarbon $(0.75 \mathrm{mM})$ were added and the mixture was stirred for $6 \mathrm{~h}$ in an oil bath at $65^{\circ} \mathrm{C}$. The reaction was quenched with water and the crude product extracted with ethyl acetate (EtOAc) three times. The combined extracts were dried over $\mathrm{Na}_{2} \mathrm{SO}_{4}$ and concentrated under reduced pressure. The residue was purified using silica gel (300-400 mesh) column chromatography with a petroleum ether:EtOAc (50:1 to 30:1) eluent to afford compounds 1a-9a and $\mathbf{1 b}-\mathbf{6} \mathbf{b}$.

5,5'-Diallyl-2-methoxy-1,1'-biphenyl-2'-ol (1a). Yield: 48.1\%, yellow oil, ${ }^{1} \mathrm{H}-\mathrm{NMR}\left(\mathrm{CD}_{3} \mathrm{OD}\right.$, $500 \mathrm{MHz}) \delta 7.13(1 \mathrm{H}, \mathrm{dd}, J=7.0,1.9 \mathrm{~Hz}, \mathrm{H}-4), 7.00(1 \mathrm{H}, \mathrm{d}, J=1.9 \mathrm{~Hz}, \mathrm{H}-3), 6.97(1 \mathrm{H}, \mathrm{dd}$, $\left.J=6.9,2.0 \mathrm{~Hz}, \mathrm{H}-4^{\prime}\right), 6.96(1 \mathrm{H}, \mathrm{d}, J=6.9 \mathrm{~Hz}, \mathrm{H}-6), 6.90\left(1 \mathrm{H}, \mathrm{d}, J=1.9 \mathrm{~Hz}, \mathrm{H}-3^{\prime}\right), 6.78(1 \mathrm{H}, \mathrm{d}$, $\left.J=6.9 \mathrm{~Hz}, \mathrm{H}-6^{\prime}\right), 5.96\left(2 \mathrm{H}, \mathrm{m}, \mathrm{H}-8, \mathrm{H}-8^{\prime}\right), 5.07(2 \mathrm{H}, \mathrm{m}, \mathrm{H}-9), 5.02\left(2 \mathrm{H}, \mathrm{m}, \mathrm{H}-9^{\prime}\right), 3.74(3 \mathrm{H}, \mathrm{s}$, $\mathrm{H}-10), 3.34(2 \mathrm{H}, \mathrm{d}, J=5.6 \mathrm{~Hz}), 3.30(2 \mathrm{H}, \mathrm{d}, J=5.3 \mathrm{~Hz}) ;{ }^{13} \mathrm{C}$ NMR $\left(\mathrm{CD}_{3} \mathrm{OD}, 125 \mathrm{MHz}\right) \delta 155.3$ (C-2), $152.4\left(\mathrm{C}-2^{\prime}\right), 138.1\left(\mathrm{C}-8^{\prime}\right), 137.9$ (C-8), $132.0\left(\mathrm{C}-5^{\prime}\right), 131.4(\mathrm{C}-5), 131.1\left(\mathrm{C}-6^{\prime}\right), 130.8$ (C-6), 128.2 (C-4'), 128.1 (C-4), 127.8 (C-1), $126.1\left(\mathrm{C}-1^{\prime}\right), 115.4\left(\mathrm{C}-3^{\prime}\right), 114.2\left(\mathrm{C}-9^{\prime}\right), 114.0(\mathrm{C}-9), 111.2$ (C-3), 54.9 (C-10), 39.0 (C-7, C-7'); ESIMS: $m / z 281.17$ [M + H] ${ }^{+}$.

5,5'-Diallyl-2,2'-dimethoxy-1,1'-biphenyl (1b). Yield: $20.9 \%$, yellow oil, ${ }^{1} \mathrm{H}-\mathrm{NMR}\left(\mathrm{CD}_{3} \mathrm{OD}\right.$, $500 \mathrm{MHz}) \delta 7.10\left(2 \mathrm{H}, \mathrm{dd}, J=7.1,2.0 \mathrm{~Hz}, \mathrm{H}-4, \mathrm{H}-4^{\prime}\right), 6.92\left(2 \mathrm{H}, \mathrm{d}, J=1.1 \mathrm{~Hz}, \mathrm{H}-6, \mathrm{H}-6^{\prime}\right), 6.91$ $\left(2 \mathrm{H}, \mathrm{d}, J=3.9 \mathrm{~Hz}, \mathrm{H}-3, \mathrm{H}-3^{\prime}\right), 5.96\left(2 \mathrm{H}, \mathrm{m}, \mathrm{H}-8, \mathrm{H}-8^{\prime}\right), 5.03\left(4 \mathrm{H}, \mathrm{m}, \mathrm{H}-9, \mathrm{H}-9^{\prime}\right), 3.69(6 \mathrm{H}, \mathrm{s}$, H-10, H-10'), $3.32\left(4 \mathrm{H}, \mathrm{d}, J=5.6 \mathrm{~Hz}, \mathrm{H}-7, \mathrm{H}^{-} 7^{\prime}\right) ;{ }^{13} \mathrm{C}$ NMR $\left(\mathrm{CD}_{3} \mathrm{OD}, 125 \mathrm{MHz}\right): \delta 155.5(\mathrm{C}-2$, C-2' $), 137.9\left(\mathrm{C}-8, \mathrm{C}-8^{\prime}\right), 131.6\left(\mathrm{C}-5, \mathrm{C}-5^{\prime}\right), 131.1\left(\mathrm{C}-6, \mathrm{C}-6^{\prime}\right), 128.1\left(\mathrm{C}-4, \mathrm{C}-4^{\prime}\right), 128.0\left(\mathrm{C}-1, \mathrm{C}-1^{\prime}\right)$, 114.2 (C-9, C-9'), 110.9 (C-3, C-3'), 54.8 (C-10, C-10'), 38.9 (C-7, C-7'); ESIMS: $m / z 295.18$ $[\mathrm{M}+\mathrm{H}]^{+}$.

5,5'-Diallyl-2-ethoxy-1, $1^{\prime}$-biphenyl-2'-ol (2a). Yield: 73.6\%, yellow oil, ${ }^{1} \mathrm{H}-\mathrm{NMR}$ (DMSO$\left.d_{6}, 500 \mathrm{MHz}\right): \delta 8.86(1 \mathrm{H}, \mathrm{s},-\mathrm{OH}), 7.07(1 \mathrm{H}, \mathrm{d}, J=2.4 \mathrm{~Hz}, \mathrm{H}-6), 7.05\left(1 \mathrm{H}, \mathrm{d}, J=2.3 \mathrm{~Hz}, \mathrm{H}-6^{\prime}\right)$, $6.95(1 \mathrm{H}, \mathrm{d}, J=8.4 \mathrm{~Hz}, \mathrm{H}-3), 6.95(1 \mathrm{H}, \mathrm{dd}, J=2.3,2.3 \mathrm{~Hz}, \mathrm{H}-4), 6.90(1 \mathrm{H}, \mathrm{dd}, J=2.4,2.3 \mathrm{~Hz}$, H-4' $), 6.79\left(1 \mathrm{H}, \mathrm{d}, J=8.1 \mathrm{~Hz}, \mathrm{H}-3^{\prime}\right), 5.94\left(2 \mathrm{H}, \mathrm{m}, \mathrm{H}-8, \mathrm{H}-8^{\prime}\right), 5.05\left(4 \mathrm{H}, \mathrm{m}, \mathrm{H}-9, \mathrm{H}-9^{\prime}\right), 3.96$ $(2 \mathrm{H}, \mathrm{q}, J=7.0 \mathrm{~Hz}, \mathrm{H}-10), 3.30\left(4 \mathrm{H}, \mathrm{d}, J=6.8 \mathrm{~Hz}, \mathrm{H}-7, \mathrm{H}-7^{\prime}\right), 1.17(3 \mathrm{H}, \mathrm{t}, J=6.9 \mathrm{~Hz}, \mathrm{H}-11)$; ${ }^{13} \mathrm{C}$ NMR (DMSO- $\left.d_{6}, 125 \mathrm{MHz}\right): \delta 154.3(\mathrm{C}-2), 152.8\left(\mathrm{C}-2^{\prime}\right), 138.3\left(\mathrm{C}-8^{\prime}\right), 138.1$ (C-8), 131.4 $\left(\mathrm{C}-5^{\prime}\right), 131.3(\mathrm{C}-5), 131.0\left(\mathrm{C}-6^{\prime}\right), 129.2(\mathrm{C}-6), 128.0\left(\mathrm{C}-4^{\prime}\right), 127.9$ (C-1, C-4), $125.4\left(\mathrm{C}-1^{\prime}\right), 115.4$ $\left(\mathrm{C}-9, \mathrm{C}^{\prime} 9^{\prime}\right), 115.2\left(\mathrm{C}-3^{\prime}\right), 112.8(\mathrm{C}-3), 63.6$ (C-10), 38.7 (C-7, C-7'), 14.7 (C-11); ESIMS: $m / z$ $317.15[\mathrm{M}+\mathrm{Na}]^{+}$.

5,5'-Diallyl-2,2'-diethoxy-1, $1^{\prime}$-biphenyl (2b). Yield: 6.8\%, yellow oil, ${ }^{1} \mathrm{H}$-NMR (DMSO- $d_{6}$, $500 \mathrm{MHz}): \delta 7.07\left(2 \mathrm{H}, \mathrm{dd}, J=8.3,2.0 \mathrm{~Hz}, \mathrm{H}-4, \mathrm{H}-4^{\prime}\right), 6.94\left(2 \mathrm{H}, \mathrm{d}, J=8.3 \mathrm{~Hz}, \mathrm{H}-3, \mathrm{H}-3^{\prime}\right), 6.94$ $\left(2 \mathrm{H}, \mathrm{s}, \mathrm{H}-6, \mathrm{H}-6^{\prime}\right), 5.95\left(2 \mathrm{H}, \mathrm{m}, \mathrm{H}-8, \mathrm{H}-8^{\prime}\right), 5.05\left(4 \mathrm{H}, \mathrm{m}, \mathrm{H}-9, \mathrm{H}-9^{\prime}\right), 3.95(4 \mathrm{H}, \mathrm{q}, J=7.0 \mathrm{~Hz}$, $\left.\mathrm{H}-10, \mathrm{H}-10^{\prime}\right), 3.31\left(4 \mathrm{H}, \mathrm{d}, J=6.8 \mathrm{~Hz}, \mathrm{H}-7, \mathrm{H}-7^{\prime}\right), 1.17\left(6 \mathrm{H}, \mathrm{t}, J=6.9 \mathrm{~Hz}, \mathrm{H}-11, \mathrm{H}-11^{\prime}\right) ;{ }^{13} \mathrm{C}$ NMR (DMSO- $\left.d_{6}, 125 \mathrm{MHz}\right): \delta 154.3$ (C-2, C-2') 138.1 (C-8, C-8'), 131.2 (C-5, C-5'), 130.9 $\left(\mathrm{C}-6, \mathrm{C}-6^{\prime}\right), 128.1\left(\mathrm{C}-4, \mathrm{C}-4^{\prime}\right), 127.6\left(\mathrm{C}-1, \mathrm{C}-1^{\prime}\right), 115.4\left(\mathrm{C}-9, \mathrm{C}-9^{\prime}\right), 112.2\left(\mathrm{C}-3, \mathrm{C}-3^{\prime}\right), 63.3(\mathrm{C}-10$, C-10'), $38.6\left(\mathrm{C}-7, \mathrm{C}-7^{\prime}\right), 14.7\left(\mathrm{C}-11, \mathrm{C}-11^{\prime}\right)$; ESIMS: $m / z 345.18$ [M + Na] ${ }^{+}$.

5,5'-Diallyl-2-benzyloxy-1,1'-biphenyl-2'-ol (3a). Yield: 68.8\%, pale yellow oil, ${ }^{1} \mathrm{H}-\mathrm{NMR}$ (DMSO- $\left.d_{6}, 500 \mathrm{MHz}\right): \delta 9.04(1 \mathrm{H}, \mathrm{s},-\mathrm{OH}), 7.31(5 \mathrm{H}, \mathrm{m}, \mathrm{Ar}-\mathrm{H}), 7.08(1 \mathrm{H}, \mathrm{m}, \mathrm{H}-3), 7.02(2 \mathrm{H}$, m, H-6, H-6') $6.94\left(2 \mathrm{H}, \mathrm{dd}, J=5.7,2.3 \mathrm{~Hz}, \mathrm{H}-4, \mathrm{H}-4^{\prime}\right), 6.83\left(1 \mathrm{H}, \mathrm{m}, \mathrm{H}-3^{\prime}\right), 5.93(2 \mathrm{H}, \mathrm{m}, \mathrm{H}-8$, H-8 $\left.{ }^{\prime}\right), 5.09(2 \mathrm{H}, \mathrm{d}, J=17.1 \mathrm{~Hz}, \mathrm{H}-9), 5.03(2 \mathrm{H}, \mathrm{s}, \mathrm{H}-10), 5.00\left(2 \mathrm{H}, \mathrm{d}, J=11.0 \mathrm{~Hz}, \mathrm{H}-9^{\prime}\right), 3.32$ $(2 \mathrm{H}, \mathrm{d}, J=6.8 \mathrm{~Hz}, \mathrm{H}-7), 3.26\left(2 \mathrm{H}, \mathrm{d}, J=6.7 \mathrm{~Hz}, \mathrm{H}-7^{\prime}\right) ;{ }^{13} \mathrm{C}$ NMR (DMSO- $\left.d_{6}, 125 \mathrm{MHz}\right): \delta$ 154.0 (C-2'), 152.9 (C-2), 138.2 (C-8'), 138.0 (C-8), 137.5 (C-11), 131.4 (C-5'), 131.3 (C-5, C-6'), 129.2 (C-6), 128.1 (C-4, C-13, C-15, C-4'), 127.9 (C-1), 127.4 (C-14), 127.0 (C-12, C-16, C-1'), $115.5\left(\mathrm{C}-9^{\prime}\right), 115.3\left(\mathrm{C}-3^{\prime}\right), 115.2$ (C-9), 112.9 (C-3), 69.4 (C-10), 38.7 (C-7, C-7'); HRESIMS: calcd. for $\mathrm{C}_{25} \mathrm{H}_{24} \mathrm{O}_{2} \mathrm{Na}^{+}[\mathrm{M}+\mathrm{Na}]^{+} 379.1669$, found 379.1673 .

5,5'-Diallyl-2,2'-bis (benzyloxy)-1,1'-biphenyl (3b). Yield: 6.74\%, rhombic white crystal; ${ }^{1} \mathrm{H}-\mathrm{NMR}$ (DMSO- $\left.d_{6}, 500 \mathrm{MHz}\right): \delta 7.25(10 \mathrm{H}, \mathrm{m}, \mathrm{Ar}-\mathrm{H}), 7.10(2 \mathrm{H}, \mathrm{dd}, J=8.3,2.2 \mathrm{~Hz}, \mathrm{H}-4$, H-4') $7.06\left(2 \mathrm{H}, \mathrm{s}, \mathrm{H}-6, \mathrm{H}-6^{\prime}\right), 7.05\left(2 \mathrm{H}, \mathrm{d}, J=8.4 \mathrm{~Hz}, \mathrm{H}-3, \mathrm{H}-3^{\prime}\right), 5.96\left(2 \mathrm{H}, \mathrm{m}, \mathrm{H}-8, \mathrm{H}-8^{\prime}\right), 5.04$ $\left(4 \mathrm{H}, \mathrm{m}, \mathrm{H}-9, \mathrm{H}-9^{\prime}\right), 5.01\left(4 \mathrm{H}, \mathrm{s}, \mathrm{H}-10, \mathrm{H}-10^{\prime}\right), 3.32\left(4 \mathrm{H}, \mathrm{d}, J=6.8 \mathrm{~Hz}, \mathrm{H}-7, \mathrm{H}-7^{\prime}\right) ;{ }^{13} \mathrm{C}$ NMR (DMSO- $\left.d_{6}, 125 \mathrm{MHz}\right): \delta 154.0\left(\mathrm{C}-2, \mathrm{C}-2^{\prime}\right), 138.0\left(\mathrm{C}-11, \mathrm{C}-11^{\prime}\right), 137.4$ (C-8, C-8'), 131.4 (C-5, C-5'), $131.3($ C-6, C-6' $), 128.3$ (C-4, C-4' $), 128.2$ (C-13, C-15, C-13' , C-15'), 127.5 (C-14, C-14'), 
127.4 (C-1, C-1'), 126.9 (C-12, C-16, C-12', C-16'), 115.5 (C-9, C-9'), 112.8 (C-3, C-3'), 69.4 (C-10, C-10'), $38.7\left(\mathrm{C}-7, \mathrm{C}-7^{\prime}\right)$; HRESIMS: calcd. for $\mathrm{C}_{32} \mathrm{H}_{30} \mathrm{O}_{2} \mathrm{Na}^{+}[\mathrm{M}+\mathrm{H}]^{+} 447.2283$, found 447.2280.

5,5'-Diallyl-2-((2-fluorobenzyl)oxy)-1,1'-biphenyl-2'-ol (4a). Yield: 62.3\%, pale yellow oils; ${ }^{1} \mathrm{H}-\mathrm{NMR}$ (DMSO- $\left.d_{6}, 500 \mathrm{MHz}\right): \delta 9.03(1 \mathrm{H}, \mathrm{s},-\mathrm{OH}), 7.39(1 \mathrm{H}, \mathrm{m}, \mathrm{H}-13), 7.34(1 \mathrm{H}, \mathrm{m}, \mathrm{H}-14)$, $7.18\left(1 \mathrm{H}, \mathrm{m}, \mathrm{H}-4^{\prime}\right), 7.14(1 \mathrm{H}, \mathrm{m}, \mathrm{H}-3), 7.08(1 \mathrm{H}, \mathrm{m}, \mathrm{H}-15), 7.07(1 \mathrm{H}, \mathrm{m}, \mathrm{H}-6), 7.03(1 \mathrm{H}, \mathrm{m}$, H-6'), $6.92(2 \mathrm{H}, \mathrm{m}, \mathrm{H}-4, \mathrm{H}-16), 6.81$ (1H, m, H-3'), $5.92\left(2 \mathrm{H}, \mathrm{m}, \mathrm{H}-8, \mathrm{H}-8^{\prime}\right), 5.09$ (2H, m, H-9), $5.08(2 \mathrm{H}, \mathrm{s}, \mathrm{H}-10), 5.03\left(2 \mathrm{H}, \mathrm{m}, \mathrm{H}-9^{\prime}\right), 3.33(2 \mathrm{H}, \mathrm{d}, J=6.8 \mathrm{~Hz}, \mathrm{H}-7), 3.24(2 \mathrm{H}, \mathrm{d}, J=6.7 \mathrm{~Hz}$, H-7'); ${ }^{13} \mathrm{C}$ NMR (DMSO- $\left.d_{6}, 125 \mathrm{MHz}\right): \delta 158.8\left(\mathrm{~d},{ }^{1} J_{\mathrm{CF}}=243.7 \mathrm{~Hz}, \mathrm{C}-12\right), 153.8\left(\mathrm{C}-2^{\prime}\right), 152.9$ (C-2), 138.2 (C-8', C-8), $138.0\left(\mathrm{C}^{-} 5^{\prime}\right), 131.6(\mathrm{C}-5), 131.5\left(\mathrm{C}-6^{\prime}\right), 131.3(\mathrm{C}-6), 129.7\left(\mathrm{~d},{ }^{3} \mathrm{~J}_{\mathrm{CF}}=4.1\right.$ $\mathrm{Hz}, \mathrm{C}-14), 129.6\left(\mathrm{C}-4^{\prime}\right), 129.2(\mathrm{C}-4), 128.1\left(\mathrm{~d},{ }^{3} J_{\mathrm{CF}}=4.9 \mathrm{~Hz}, \mathrm{C}-16\right), 128.0\left(\mathrm{~d},{ }^{2} J_{\mathrm{CF}}=12.2 \mathrm{~Hz}\right.$, C-11), $125.0(\mathrm{C}-1), 124.4\left(\mathrm{C}-1^{\prime}\right), 124.3\left(\mathrm{~d},{ }^{4} J_{\mathrm{CF}}=3.2 \mathrm{~Hz}, \mathrm{C}-15\right), 115.5\left(\mathrm{C}-3^{\prime}\right), 115.4\left(\mathrm{C}-9^{\prime}\right), 115.2$ $(\mathrm{C}-9), 115.1\left(\mathrm{~d},{ }^{2} J_{\mathrm{CF}}=20.8 \mathrm{~Hz}, \mathrm{C}-13\right), 112.9(\mathrm{C}-3), 63.6\left(\mathrm{~d},{ }^{3} J_{\mathrm{CF}}=4.0 \mathrm{~Hz}, \mathrm{C}-10\right), 38.7(\mathrm{C}-7$, C-7'); HRESIMS: calcd. for $\mathrm{C}_{25} \mathrm{H}_{23} \mathrm{FO}_{2} \mathrm{Na}^{+}[\mathrm{M}+\mathrm{Na}]^{+}$397.1574, found 397.1574.

5,5'-Diallyl-2,2'-bis ((2-fluorobenzyl)oxy)-1,1'-biphenyl (4b). Yield: $5.6 \%$, pale yellow oils; ${ }^{1} \mathrm{H}-\mathrm{NMR}$ (DMSO- $\left.d_{6}, 500 \mathrm{MHz}\right): \delta 7.33$ (2H, m, H-14, H-14'), 7.25 (2H, m, H-13, H-13'), 7.17 (2H, m, H-16, H-16'), 7.09 (2H, m, H-15, H-15'), 7.08 (4H, m, H-3, H-4, H-3', H-4'), $7.05\left(2 \mathrm{H}, \mathrm{s}, \mathrm{H}-6, \mathrm{H}-6^{\prime}\right), 5.90\left(2 \mathrm{H}, \mathrm{m}, \mathrm{H}-8, \mathrm{H}-8^{\prime}\right), 5.03\left(4 \mathrm{H}, \mathrm{m}, \mathrm{H}-9, \mathrm{H}-9^{\prime}\right), 5.03(4 \mathrm{H}, \mathrm{s}, \mathrm{H}-10$, $\left.\mathrm{H}-10^{\prime}\right), 3.30\left(4 \mathrm{H}, \mathrm{d}, J=6.7 \mathrm{~Hz}, \mathrm{H}-7, \mathrm{H}-7^{\prime}\right) ;{ }^{13} \mathrm{C}$ NMR (DMSO- $\left.d_{6}, 125 \mathrm{MHz}\right): \delta 158.8(\mathrm{~d}$, $\left.{ }^{1} J_{\mathrm{CF}}=244.0 \mathrm{~Hz}, \mathrm{C}-12, \mathrm{C}-12^{\prime}\right), 153.7\left(\mathrm{C}-2, \mathrm{C}-2^{\prime}\right), 137.9\left(\mathrm{C}-8, \mathrm{C}-8^{\prime}\right), 131.6\left(\mathrm{C}-5, \mathrm{C}-6, \mathrm{C}-5^{\prime}, \mathrm{C}-6^{\prime}\right)$, $129.8\left(\mathrm{~d}^{3}{ }^{3} J_{\mathrm{CF}}=8.2 \mathrm{~Hz}, \mathrm{C}-16, \mathrm{C}-16^{\prime}\right), 129.6\left(\mathrm{~d},{ }^{3} J_{\mathrm{CF}}=4.1 \mathrm{~Hz}, \mathrm{C}-14, \mathrm{C}-14^{\prime}\right), 128.4\left(\mathrm{C}-4, \mathrm{C}-4^{\prime}\right)$, 127.2 (C-1, C-1'), $124.2\left(\mathrm{~d},{ }^{4} J_{\mathrm{CF}}=3.5 \mathrm{~Hz}, \mathrm{C}-15, \mathrm{C}-15^{\prime}\right), 124.1\left(\mathrm{~d},{ }^{2} J_{\mathrm{CF}}=15.1 \mathrm{~Hz}, \mathrm{C}-11, \mathrm{C}-11^{\prime}\right)$, $115.5\left(\mathrm{C}-9, \mathrm{C}-9^{\prime}\right), 115.2\left(\mathrm{~d},{ }^{2} J_{\mathrm{CF}}=20.8 \mathrm{~Hz}, \mathrm{C}-13, \mathrm{C}-13^{\prime}\right), 112.8\left(\mathrm{C}-3, \mathrm{C}-3^{\prime}\right), 63.7\left(\mathrm{~d},{ }^{3} J_{\mathrm{CF}}=4.0\right.$ $\left.\mathrm{Hz}, \mathrm{C}-10, \mathrm{C}-10^{\prime}\right), 38.6\left(\mathrm{C}-7, \mathrm{C}-7^{\prime}\right)$; HRESIMS: calcd. for $\mathrm{C}_{32} \mathrm{H}_{28} \mathrm{~F}_{2} \mathrm{O}_{2} \mathrm{Na}^{+}[\mathrm{M}+\mathrm{Na}]^{+} 505.1950$, found 505.1951 .

5,5'-Diallyl-2-((3-fluorobenzyl)oxy)-1,1'-biphenyl-2'-ol (5a). Yield: 65.9\%, pale yellow oils; ${ }^{1} \mathrm{H}-\mathrm{NMR}$ (DMSO- $\left.d_{6}, 500 \mathrm{MHz}\right): \delta 9.08(1 \mathrm{H}, \mathrm{s},-\mathrm{OH}), 7.34(1 \mathrm{H}, \mathrm{m}, \mathrm{H}-15), 7.14(2 \mathrm{H}, \mathrm{m}, \mathrm{H}-6$, H-6') 7.07 (2H, m, H-4, H-16), 7.01 (2H, m, H-3, H-14), 6.95 (2H, m, H-3', H-4'), $6.84(1 \mathrm{H}$, $\mathrm{dd}, J=8.1,3.4 \mathrm{~Hz}, \mathrm{H}-12), 5.94\left(2 \mathrm{H}, \mathrm{m}, \mathrm{H}-8, \mathrm{H}-8^{\prime}\right), 5.09(2 \mathrm{H}, \mathrm{m}, \mathrm{H}-9), 5.06(2 \mathrm{H}, \mathrm{s}, \mathrm{H}-10)$, $5.04\left(2 \mathrm{H}, \mathrm{m}, \mathrm{H}-9^{\prime}\right), 3.33(2 \mathrm{H}, \mathrm{d}, J=6.8 \mathrm{~Hz}, \mathrm{H}-7), 3.27\left(2 \mathrm{H}, \mathrm{d}, J=6.7 \mathrm{~Hz}, \mathrm{H}-7^{\prime}\right) ;{ }^{13} \mathrm{C}$ NMR (DMSO- $\left.d_{6}, 125 \mathrm{MHz}\right): \delta 161.2\left(\mathrm{~d},{ }^{1} \mathrm{~J}_{\mathrm{CF}}=241.6 \mathrm{~Hz}, \mathrm{C}-13\right), 153.8\left(\mathrm{C}-2^{\prime}\right), 153.0(\mathrm{C}-2), 140.5(\mathrm{~d}$, $\left.{ }^{3} J_{\mathrm{CF}}=7.5 \mathrm{~Hz}, \mathrm{C}-11\right), 138.2\left(\mathrm{C}-8^{\prime}\right), 138.0(\mathrm{C}-8), 131.5\left(\mathrm{C}-5^{\prime}\right), 131.4(\mathrm{C}-5), 131.2\left(\mathrm{C}-6^{\prime}\right), 130.1(\mathrm{~d}$, $\left.{ }^{3} J_{\mathrm{CF}}=8.2 \mathrm{~Hz}, \mathrm{C}-15\right), 129.3(\mathrm{C}-6), 128.2\left(\mathrm{C}-4^{\prime}\right), 128.1(\mathrm{C}-4), 128.0(\mathrm{C}-1), 125.2\left(\mathrm{C}-1^{\prime}\right), 122.8(\mathrm{~d}$, $\left.{ }^{4} J_{\mathrm{CF}}=2.7 \mathrm{~Hz}, \mathrm{C}-16\right), 115.5\left(\mathrm{C}-3^{\prime}\right), 115.3\left(\mathrm{C}-9^{\prime}\right), 115.2(\mathrm{C}-9), 114.2\left(\mathrm{~d},{ }^{2} J_{\mathrm{CF}}=20.8 \mathrm{~Hz}, \mathrm{C}-14\right)$, $113.6\left(\mathrm{~d},{ }^{2} J_{\mathrm{CF}}=21.8 \mathrm{~Hz}, \mathrm{C}-12\right), 112.8(\mathrm{C}-3), 68.5$ (C-10), 38.7 (C-7, C-7'); HRESIMS: calcd. for $\mathrm{C}_{25} \mathrm{H}_{23} \mathrm{FO}_{2} \mathrm{Na}^{+}[\mathrm{M}+\mathrm{Na}]^{+}$397.1574, found 397.1575.

5,5'-Diallyl-2,2'-bis ((3-fluorobenzyl)oxy)-1,1'-biphenyl (5b). Yield: $2.8 \%$, pale yellow oils; ${ }^{1} \mathrm{H}-\mathrm{NMR}$ (DMSO- $\left.d_{6}, 500 \mathrm{MHz}\right): \delta 7.30\left(2 \mathrm{H}, \mathrm{m}, \mathrm{H}-15, \mathrm{H}-15^{\prime}\right), 7.12(2 \mathrm{H}, \mathrm{dd}, J=8.35,2.25 \mathrm{~Hz}$, H-4, H-4' $), 7.07$ (2H, s, H-6, H-6'), $7.06(6 \mathrm{H}, \mathrm{m}, \mathrm{Ar}-\mathrm{H}), 7.00\left(2 \mathrm{H}, \mathrm{d}, J=10.1 \mathrm{~Hz}, \mathrm{H}-3, \mathrm{H}-3^{\prime}\right)$, $5.94\left(2 \mathrm{H}, \mathrm{m}, \mathrm{H}-8, \mathrm{H}-8^{\prime}\right), 5.03\left(4 \mathrm{H}, \mathrm{m}, \mathrm{H}-9, \mathrm{H}^{\prime} 9^{\prime}\right), 5.03\left(4 \mathrm{H}, \mathrm{s}, \mathrm{H}-10, \mathrm{H}-10^{\prime}\right), 3.32(4 \mathrm{H}, \mathrm{d}, J=6.7$ $\left.\mathrm{Hz}, \mathrm{H}-7, \mathrm{H}-7^{\prime}\right) ;{ }^{13} \mathrm{C}$ NMR (DMSO- $\left.d_{6}, 125 \mathrm{MHz}\right): \delta 161.1$ (d, ${ }^{1} J_{\mathrm{CF}}=241.9 \mathrm{~Hz}, \mathrm{C}-13, \mathrm{C}-13^{\prime}$ ), $153.7\left(\mathrm{C}-2, \mathrm{C}-2^{\prime}\right), 140.4\left(\mathrm{~d},{ }^{3} J_{\mathrm{CF}}=7.4 \mathrm{~Hz}, \mathrm{C}-11, \mathrm{C}-11^{\prime}\right), 137.9\left(\mathrm{C}-8, \mathrm{C}-8^{\prime}\right), 131.6\left(\mathrm{C}-5, \mathrm{C}-5^{\prime}\right)$, $131.4\left(\mathrm{C}-6, \mathrm{C}-6^{\prime}\right), 130.2\left(\mathrm{~d},{ }^{3} J_{\mathrm{CF}}=8.1 \mathrm{~Hz}, \mathrm{C}-15, \mathrm{C}-15^{\prime}\right), 128.4\left(\mathrm{C}-4, \mathrm{C}-4^{\prime}\right), 127.5\left(\mathrm{C}-1, \mathrm{C}-1^{\prime}\right)$, $122.7\left(\mathrm{~d},{ }^{4} J_{\mathrm{CF}}=2.5 \mathrm{~Hz}, \mathrm{C}-16, \mathrm{C}-16^{\prime}\right), 115.6\left(\mathrm{C}-9, \mathrm{C}-9^{\prime}\right), 114.2\left(\mathrm{~d},{ }^{2} J_{\mathrm{CF}}=20.8 \mathrm{~Hz}, \mathrm{C}-14, \mathrm{C}-14^{\prime}\right)$, $113.5\left(\mathrm{~d},{ }^{2} J_{\mathrm{CF}}=21.9 \mathrm{~Hz}, \mathrm{C}-12, \mathrm{C}-12^{\prime}\right), 112.8\left(\mathrm{C}-3, \mathrm{C}-3^{\prime}\right), 68.5\left(\mathrm{C}-10, \mathrm{C}-10^{\prime}\right), 38.6\left(\mathrm{C}-7, \mathrm{C}-7^{\prime}\right)$; HRESIMS: calcd. for $\mathrm{C}_{32} \mathrm{H}_{28} \mathrm{~F}_{2} \mathrm{O}_{2} \mathrm{Na}^{+}[\mathrm{M}+\mathrm{Na}]^{+}$505.1950, found 505.1953 .

5,5'-Diallyl-2-((4-fluorobenzyl)oxy)-1,1'-biphenyl-2'-ol (6a). Yield: 34.7\%, pale yellow oils; ${ }^{1} \mathrm{H}-\mathrm{NMR}$ (DMSO- $\left.d_{6}, 500 \mathrm{MHz}\right): \delta 9.04(1 \mathrm{H}, \mathrm{s},-\mathrm{OH}), 7.37(2 \mathrm{H}, \mathrm{dd}, J=8.3,5.6 \mathrm{~Hz}, \mathrm{H}-12$, $\mathrm{H}-16), 7.12(2 \mathrm{H}, \mathrm{m}, \mathrm{H}-13, \mathrm{H}-15), 7.09(1 \mathrm{H}, \mathrm{dd}, J=8.4,2.3 \mathrm{~Hz}, \mathrm{H}-4), 7.02(2 \mathrm{H}, \mathrm{d}, J=8.4 \mathrm{~Hz}$, H-3, H-3'), $6.94\left(2 \mathrm{H}, \mathrm{m}, \mathrm{H}-6, \mathrm{H}-6^{\prime}\right), 6.83\left(1 \mathrm{H}, \mathrm{m}, \mathrm{H}-4^{\prime}\right), 5.93\left(2 \mathrm{H}, \mathrm{m}, \mathrm{H}-8, \mathrm{H}-8^{\prime}\right), 5.05(4 \mathrm{H}, \mathrm{m}$, H-9, H-9'), $5.01(2 \mathrm{H}, \mathrm{s}, \mathrm{H}-10), 3.32(2 \mathrm{H}, \mathrm{d}, J=6.8 \mathrm{~Hz}, \mathrm{H}-7), 3.26\left(2 \mathrm{H}, \mathrm{d}, J=6.8 \mathrm{~Hz}, \mathrm{H}-7^{\prime}\right)$; ${ }^{13} \mathrm{C}$ NMR (DMSO- $\left.d_{6}, 125 \mathrm{MHz}\right): \delta 160.5\left(\mathrm{~d},{ }^{1} J_{\mathrm{CF}}=241.7 \mathrm{~Hz}, \mathrm{C}-14\right), 153.9\left(\mathrm{C}-2^{\prime}\right), 152.9(\mathrm{C}-2)$, $138.2\left(\mathrm{C}-8^{\prime}\right), 138.0(\mathrm{C}-8), 133.7\left(\mathrm{~d},{ }^{4} J_{\mathrm{CF}}=2.9 \mathrm{~Hz}, \mathrm{C}-11\right), 131.5\left(\mathrm{C}-5^{\prime}\right), 131.4(\mathrm{C}-5), 131.2\left(\mathrm{C}-6^{\prime}\right)$, $129.3(\mathrm{C}-6), 129.2\left(\mathrm{~d},{ }^{3} J_{\mathrm{CF}}=8.1 \mathrm{~Hz}, \mathrm{C}-12, \mathrm{C}-16\right), 128.2\left(\mathrm{C}-4^{\prime}\right), 128.1$ (C-4), 127.9 (C-1), 125.3 
(C-1'), $115.5\left(\mathrm{C}-3^{\prime}\right), 115.3\left(\mathrm{C}-9^{\prime}\right), 115.2(\mathrm{C}-9), 115.0\left(\mathrm{~d},{ }^{2} \mathrm{~J}_{\mathrm{CF}}=21.2 \mathrm{~Hz}, \mathrm{C}-13, \mathrm{C}-15\right), 113.0$ (C-3), 68.8 (C-10), $38.7\left(\mathrm{C}-7, \mathrm{C}-7^{\prime}\right)$; HRESIMS: calcd. for $\mathrm{C}_{25} \mathrm{H}_{23} \mathrm{FO}_{2} \mathrm{Na}^{+}[\mathrm{M}+\mathrm{Na}]^{+}$397.1574, found 397.1575 .

5,5'-Diallyl-2,2'-bis ((4-fluorobenzyl)oxy)-1,1'-biphenyl (6b). Yield: 4.7\%, rhombic white crystal; ${ }^{1} \mathrm{H}-\mathrm{NMR}\left(\mathrm{DMSO}-d_{6}, 500 \mathrm{MHz}\right): \delta 7.26(4 \mathrm{H}, \mathrm{m}, \mathrm{Ar}-\mathrm{H}), 7.07(4 \mathrm{H}, \mathrm{m}, \mathrm{Ar}-\mathrm{H}), 7.06$ $\left(2 \mathrm{H}, \mathrm{m}, \mathrm{H}-4, \mathrm{H}-4^{\prime}\right), 7.04\left(2 \mathrm{H}, \mathrm{m}, \mathrm{H}-3, \mathrm{H}-3^{\prime}\right), 7.03\left(2 \mathrm{H}, \mathrm{s}, \mathrm{H}-6, \mathrm{H}-6^{\prime}\right), 5.93\left(2 \mathrm{H}, \mathrm{m}, \mathrm{H}-8, \mathrm{H}-8^{\prime}\right)$, $5.04\left(4 \mathrm{H}, \mathrm{m}, \mathrm{H}-9, \mathrm{H}-9^{\prime}\right), 5.00\left(4 \mathrm{H}, \mathrm{s}, \mathrm{H}-10, \mathrm{H}-10^{\prime}\right), 3.31\left(4 \mathrm{H}, \mathrm{d}, J=6.8 \mathrm{~Hz}, \mathrm{H}-7, \mathrm{H}-7^{\prime}\right) ;{ }^{13} \mathrm{C}$ NMR (DMSO- $\left.d_{6}, 125 \mathrm{MHz}\right): \delta 160.5\left(\mathrm{~d},{ }^{1} J_{\mathrm{CF}}=241.7 \mathrm{~Hz}, \mathrm{C}-14, \mathrm{C}-14^{\prime}\right), 153.8\left(\mathrm{C}-2, \mathrm{C}-2^{\prime}\right), 138.0$ $\left(\mathrm{C}-8, \mathrm{C}-8^{\prime}\right), 133.6\left(\mathrm{~d},{ }^{4} \mathrm{~J}_{\mathrm{CF}}=2.9 \mathrm{~Hz}, \mathrm{C}-11, \mathrm{C}-11^{\prime}\right), 131.5\left(\mathrm{C}-5, \mathrm{C}-5^{\prime}\right), 131.4\left(\mathrm{C}-6, \mathrm{C}-6^{\prime}\right), 129.1(\mathrm{~d}$, $\left.{ }^{3} J_{\mathrm{CF}}=8.1 \mathrm{~Hz}, \mathrm{C}-12, \mathrm{C}-16, \mathrm{C}-12^{\prime}, \mathrm{C}-16^{\prime}\right), 128.3\left(\mathrm{C}-4, \mathrm{C}-4^{\prime}\right), 127.5\left(\mathrm{C}-1, \mathrm{C}-1^{\prime}\right), 115.5\left(\mathrm{C}-9, \mathrm{C}-9^{\prime}\right)$, $115.0\left(\mathrm{~d},{ }^{2} J_{\mathrm{CF}}=21.2 \mathrm{~Hz}, \mathrm{C}-13, \mathrm{C}-15, \mathrm{C}-13^{\prime}, \mathrm{C}-15^{\prime}\right), 112.9\left(\mathrm{C}-3, \mathrm{C}-3^{\prime}\right), 68.7\left(\mathrm{C}-10, \mathrm{C}-10^{\prime}\right), 38.6$ (C-7, C-7'); HRESIMS: calcd. for $\mathrm{C}_{32} \mathrm{H}_{28} \mathrm{~F}_{2} \mathrm{O}_{2} \mathrm{Na}^{+}[\mathrm{M}+\mathrm{Na}]^{+}$505.1950, found 505.1952.

5,5'-Diallyl-2-((2-chlorobenzyl)oxy)-1,1'-biphenyl-2'-ol (7a). Yield: 42.6\%, pale yellow oils; ${ }^{1} \mathrm{H}-\mathrm{NMR}$ (DMSO- $\left.d_{6}, 500 \mathrm{MHz}\right): \delta 9.05(1 \mathrm{H}, \mathrm{s},-\mathrm{OH}), 7.44\left(2 \mathrm{H}, \mathrm{m}, \mathrm{H}-6, \mathrm{H}-6^{\prime}\right), 7.31(1 \mathrm{H}, \mathrm{m}$, H-13), 7.26 (1H, m, H-14), 7.10 (1H, dd, J = 8.3, 2.3 Hz, H-4), 7.03 (2H, m, H-15, H-16), 6.94 $\left(2 \mathrm{H}, \mathrm{m}, \mathrm{H}-3, \mathrm{H}-4^{\prime}\right), 6.81\left(1 \mathrm{H}, \mathrm{d}, J=8.1 \mathrm{~Hz}, \mathrm{H}-3^{\prime}\right), 5.92\left(2 \mathrm{H}, \mathrm{m}, \mathrm{H}-8, \mathrm{H}-8^{\prime}\right), 5.08(2 \mathrm{H}, \mathrm{s}, \mathrm{H}-10)$, $5.03\left(4 \mathrm{H}, \mathrm{m}, \mathrm{H}-9, \mathrm{H}-9^{\prime}\right), 3.33(2 \mathrm{H}, \mathrm{d}, J=6.9 \mathrm{~Hz}, \mathrm{H}-7), 3.25\left(2 \mathrm{H}, \mathrm{d}, J=6.7 \mathrm{~Hz}, \mathrm{H}-7^{\prime}\right) ;{ }^{13} \mathrm{C}$ NMR (DMSO- $\left.d_{6}, 125 \mathrm{MHz}\right): \delta 153.7$ (C-2'), 152.9 (C-2), 138.2 (C-8'), 138.0 (C-8), 134.8 (C-11), 131.7 (C-5'), 131.5 (C-5, C-6'), 131.3 (C-6), 129.3 (C-12), 129.2 (C-4'), 129.0 (C-13, C-14), 128.2 (C-4), 128.1 (C-16), 128.0 (C-1), 127.1 (C-1'), 125.0 (C-15), $115.5\left(\right.$ C-9' $\left.^{\prime}\right), 115.3\left(\mathrm{C}-3^{\prime}\right), 115.2$ (C-9), 112.9 (C-3), 66.9 (C-10), 38.7 (C-7, C-7'); HRESIMS: calcd. for $\mathrm{C}_{25} \mathrm{H}_{23} \mathrm{ClO}_{2} \mathrm{Na}^{+}[\mathrm{M}+\mathrm{Na}]^{+}$ 413.1279, found 413.1280 .

5,5'-Diallyl-2-((3-chlorobenzyl)oxy)-1,1'-biphenyl-2'-ol (8a). Yield: 37.7\%, pale yellow oils; ${ }^{1} \mathrm{H}-\mathrm{NMR}$ (DMSO- $\left.d_{6}, 500 \mathrm{MHz}\right): \delta 9.07(1 \mathrm{H}, \mathrm{s},-\mathrm{OH}), 7.38(1 \mathrm{H}, \mathrm{s}, \mathrm{H}-12), 7.32(3 \mathrm{H}, \mathrm{m}, \mathrm{H}-14$, H-6, H-6' $), 7.09$ (1H, dd, J = 8.3, $2.3 \mathrm{~Hz}, \mathrm{H}-4), 7.02(2 \mathrm{H}, \mathrm{m}, \mathrm{H}-15, \mathrm{H}-16), 6.95$ (2H, m, H-3, $\left.\mathrm{H}-4^{\prime}\right), 6.84\left(1 \mathrm{H}, \mathrm{d}, J=8.2 \mathrm{~Hz}, \mathrm{H}-3^{\prime}\right), 5.94\left(2 \mathrm{H}, \mathrm{m}, \mathrm{H}-8, \mathrm{H}-8^{\prime}\right), 5.05(2 \mathrm{H}, \mathrm{s}, \mathrm{H}-10), 5.04(4 \mathrm{H}, \mathrm{m}$, H-9, H-9' $), 3.33(2 \mathrm{H}, \mathrm{d}, J=6.8 \mathrm{~Hz}, \mathrm{H}-7), 3.28\left(2 \mathrm{H}, \mathrm{d}, J=6.8 \mathrm{~Hz}, \mathrm{H}-7^{\prime}\right) ;{ }^{13} \mathrm{C}$ NMR (DMSO- $d_{6}$, $125 \mathrm{MHz}$ ): $\delta 153.7$ (C-2'), 152.9 (C-2), 140.2 (C-11), 138.2 (C-8'), 138.0 (C-8), 133.0 (C-13), 131.6 (C-5'), 131.4 (C-5), 131.2 (C-6'), 130.0 (C-6), 129.3 (C-15), 128.3 (C-14), 128.1 (C-4'), 128.0 (C-4), 127.3 (C-1), 126.7 (C-1'), 125.4 (C-12), 125.2 (C-16), $115.5\left(\mathrm{C}-9^{\prime}\right), 115.4\left(\mathrm{C}-3^{\prime}\right)$, 115.2 (C-9), 113.2 (C-3), 68.5 (C-10), 38.7 (C-7, C-7'); HRESIMS: calcd. for $\mathrm{C}_{25} \mathrm{H}_{23} \mathrm{ClO}_{2} \mathrm{Na}^{+}$ $[\mathrm{M}+\mathrm{Na}]^{+}$413.1279, found 413.1281.

5,5'-Diallyl-2-((4-chlorobenzyl)oxy)-1,1'-biphenyl-2'-ol (9a). Yield: 37.7\%, pale yellow oils; ${ }^{1} \mathrm{H}-\mathrm{NMR}$ (DMSO-d $\left.6,500 \mathrm{MHz}\right): \delta 9.04$ (1H, s, -OH), 7.35 (4H, m, H-6, H-13, H-15, H-6'), $7.08(1 \mathrm{H}, \mathrm{dd}, J=8.5,2.3 \mathrm{~Hz}, \mathrm{H}-4), 7.01(2 \mathrm{H}, \mathrm{m}, \mathrm{H}-12, \mathrm{H}-16), 6.93\left(2 \mathrm{H}, \mathrm{m}, \mathrm{H}-3, \mathrm{H}-4^{\prime}\right), 6.82(1 \mathrm{H}$, $\left.\mathrm{d}, J=8.1 \mathrm{~Hz}, \mathrm{H}-3^{\prime}\right), 5.93\left(2 \mathrm{H}, \mathrm{m}, \mathrm{H}-8, \mathrm{H}-8^{\prime}\right), 5.08(2 \mathrm{H}, \mathrm{m}, \mathrm{H}-9), 5.03(2 \mathrm{H}, \mathrm{s}, \mathrm{H}-10), 4.99(2 \mathrm{H}, \mathrm{m}$, H-9'), $3.32(2 \mathrm{H}, \mathrm{d}, J=6.8 \mathrm{~Hz}, \mathrm{H}-7), 3.27\left(2 \mathrm{H}, \mathrm{d}, J=6.8 \mathrm{~Hz}, \mathrm{H}-7^{\prime}\right) ;{ }^{13} \mathrm{C}$ NMR (DMSO- ${ }_{6}, 125$ MHz): $\delta 153.8$ (C-2'), 152.9 (C-2), 138.3 (C-8'), 138.0 (C-8), 136.6 (C-11), 132.0 (C-5'), 131.5 (C-14), 131.4 (C-5), 131.2 (C-6'), 129.3 (C-6), 128.9 (C-12, C-16), 128.2 (C-4'), 128.1 (C-4, C-13, C-15), 127.9 (C-1), 125.2 (C-1'), 115.5 (C-9'), $115.3\left(\mathrm{C}-3^{\prime}\right), 115.2$ (C-9), 112.9 (C-3), 68.7 (C-10), 38.7 (C-7, C-7'); HRESIMS: calcd. for $\mathrm{C}_{25} \mathrm{H}_{23} \mathrm{ClO}_{2} \mathrm{Na}^{+}[\mathrm{M}+\mathrm{Na}]^{+} 413.1279$, found 413.1280 .

\subsection{MTT Assay}

Human breast cancer (MDA-MB-231 and MCF-7), nasopharyngeal carcinoma (CNE2Z), and hepatocellular carcinoma (SMMC-7721) cell lines were cultured in RPMI-1640 medium or DMEM that were supplemented with $10 \%$ fetal bovine serum and $1 \%$ penicillinstreptomycin in a $5 \% \mathrm{CO}_{2}$ incubator at $37^{\circ} \mathrm{C}$. All cells were seeded in 96-well plates at a density of 5000 cells per well and treated with various concentrations $(0,6.25,12.5,25$, and $50 \mu \mathrm{M}$ ) of the derivatives for $72 \mathrm{~h}$. Taxol was used as a positive control. Cytotoxic activity was evaluated using standard MTT assay procedures as previously described. (All samples were lyophilized prior to MTT assay because of solvent contaminants peaks in the NMR spectra) 


\subsection{Wound-Healing Assay}

MDA-MB-231 cells were seeded in 6-well plates at a density of $6 \times 10^{5}$ cells per well. The monolayered cells were wounded by scratching with $100 \mu \mathrm{L}$ pipette tips, then washed with phosphate-buffered saline (PBS). The PBS was then replaced with serumfree RPMI-1640 containing the compound of interest. The images were taken at $0 \mathrm{~h}$ and $24 \mathrm{~h}$ after incubation for $24 \mathrm{~h}$ at $37^{\circ} \mathrm{C}$. The wound assay values were obtained from three randomly selected fields. Similar patterns of inhibition were observed in three independent experiments.

\subsection{Cell Migration Assay}

Cell migration assays were performed using a 24-well plate with $8.0 \mu \mathrm{m}$ pore membrane inserts (Corning, NY, USA) without Matrigel. MDA-MB-231 cells were added to the upper chambers at a concentration of $2.5 \times 10^{5}$ cells per well and incubated for $24 \mathrm{~h}$ after treatment with various concentrations $(0,5,10$, and $20 \mu \mathrm{M})$ of $\mathbf{6 a}$. The lower chambers were filled with conditioned media. After $24 \mathrm{~h}$, the cells that had migrated were stained with $0.1 \%$ crystal violet and photographed under a light microscope at $200 \times$ magnification. Taxol was used as a positive control.

\subsection{Cell Invasion Assay}

Cell invasion assays were performed using a 24-well plate with $8.0 \mu \mathrm{m}$ pore membrane inserts that were coated with $50 \mu \mathrm{L}$ of Matrigel (BD, Franklin Lakes, NJ, USA) and incubated at $37^{\circ} \mathrm{C}$ for $1.0 \mathrm{~h}$. MDA-MB-231 cells $\left(3 \times 10^{5}\right.$ cells per well) were added to the upper chambers and incubated with various concentrations $(0,5,10$, and $20 \mu \mathrm{M})$ of $6 \mathbf{a}$ for $36 \mathrm{~h}$. The rest of the process was the same as that described in the Section 2.5.

\subsection{Western Blotting}

MDA-MB-231 cells were cultured in 6-well plates at a density of $3 \times 10^{5}$ cells per well. After adherence, the cells were treated with various concentrations $(0,10,20$, and $40 \mu \mathrm{M})$ of $6 \mathbf{a}$ and incubated for $24 \mathrm{~h}$. The cells were harvested, washed with PBS, and proteins were extracted and quantified. The proteins were separated by SDS-PAGE and PVDF membranes. The PVDF membrane was blocked with 5\% skim milk and incubated with primary antibodies (HIF-1 $\alpha$, MMP-2, and MMP-9) at $4{ }^{\circ} \mathrm{C}$ overnight. After washing with tris-buffered saline/tween 20 buffer, the membranes were incubated with the corresponding secondary antibodies at room temperature for $2.0 \mathrm{~h}$. Protein bands were visualized using a chemiluminescence kit and detected using a gel imaging system (Bio-Rad, Hercules, CA, USA). Anti- $\beta$-actin was used as an internal control.

\subsection{Statiscal Analysis}

Statistical analysis was performed with two samples using SPSS 16.0 software (Armonk, NY, USA), and ${ }^{*} p<0.05$ or ${ }^{* *} p<0.01$ were considered statistically significant differences.

\section{Conclusions}

In summary, a series of magnolol derivatives $\mathbf{1 a}-\mathbf{9} \mathbf{a}$ and $\mathbf{1} \mathbf{b}-\mathbf{6} \mathbf{b}$ were semisynthesized by Williamson reaction and evaluated for their in vitro antiproliferative activity by MTT assay on four different human cancer cell lines (MDA-MB-231, MCF-7, CNE-2Z, and SMMC-7721). The results showed that most of the magnolol derivatives exhibited better in vitro antiproliferative activity than the precursor magnolol. Among them, compound $6 \mathrm{a}$ had the best cytotoxic activity against MDA-MB-231 cells with an $\mathrm{IC}_{50}$ value of $20.43 \mu \mathrm{M}$. Preliminary SAR indicated that $\mathrm{O}$-alkylation of magnolol at 2-OH or 2'-OH could enhance the cytotoxic activity with the benzyl with F-substituted has better activity. In addition, the results of wound-healing and transwell assays showed that 6a could also inhibit the migration of MDA-MB-231 cells very well. A more detailed mechanistic study demonstrated that 6a inhibited the migration and invasion of MDA-MB-231 cells by downregulating HIF- $1 \alpha$, MMP-2, and MMP-9 protein levels. Our findings will give some basis to the 
development of magnolol derivatives as potential anti-cancer candidates for the treatment of human cancer.

Supplementary Materials: The following are available online, 1H NMR spectrum, 13C NMR spectrum and HR-ESI-MS spectrum of Compounds.

Author Contributions: Conceptualization, C.-Z.W. and C.-H.Z.; methodology, X.-L.S., M.-L.Z., and Y.-Q.D.; software, B.-H.L. and H.M.; formal analysis, X.-L.S. and Y.-Q.D.; investigation, X.-L.S. and H.M.L.; data curation, X.-L.S. and M.-L.Z.; writing-original draft preparation, X.-L.S.; writing-review and editing, M.-L.Z. and B.-H.L.; supervision, X.-L.S., C.-Z.W., and C.-H.Z.; project administration, C.-Z.W. and X.-L.S.; funding acquisition, C.-Z.W. All authors have read and agreed to the published version of the manuscript.

Funding: This work was financially supported by the Anhui Provincial Natural Science Foundation (2008085MH284); the Education Department of Anhui Natural Science Research Project China (KJ2018A0232); 512 Talent Cultivation Plan of Bengbu Medical College (by51202202).

Institutional Review Board Statement: Not applicable.

Informed Consent Statement: Not applicable.

Data Availability Statement: The data presented in this study are available on request from the corresponding authors.

Conflicts of Interest: The authors declare no conflict of interest.

Sample Availability: Samples of the compounds $1 \mathbf{a}-\mathbf{9} \mathbf{a}$ and $\mathbf{1 b}-\mathbf{6 b}$ are available from the authors.

\section{References}

1. Yin, L.; Duan, J.J.; Bian, X.W.; Yu, S.C. Triple-negative breast cancer molecular subtyping and treatment progress. Breast Cancer Res. 2020, 22, 61. [CrossRef]

2. Loi, S.; Pommey, S.; Haibe-Kains, B.; Beavis, P.A.; Darcy, P.K.; Smyth, M.J.; Stagg, J. CD73 promotes anthracycline resistance and poor prognosis in triple negative breast cancer. Proc. Natl. Acad. Sci. USA 2013, 110, 11091-11096. [CrossRef] [PubMed]

3. Hyslop, T.; Michael, Y.; Avery, T.; Rui, H. Population and target considerations for triple-negative breast cancer clinical trials. Biomark. Med. 2013, 7, 11-21. [CrossRef] [PubMed]

4. Wang, S.; Fang, K.; Dong, G.; Chen, S.; Liu, N.; Miao, Z.; Yao, J.; Li, J.; Zhang, W.; Sheng, C. Scaffold Diversity Inspired by the Natural Product Evodiamine: Discovery of Highly Potent and Multitargeting Antitumor Agents. J. Med. Chem. 2015, 58, 6678-6696. [CrossRef] [PubMed]

5. Sun, M.; Xu, X.; Lu, Q.; Pan, Q.; Hu, X. Schisandrin B: A dual inhibitor of $P$-glycoprotein and multidrug resistance-associated protein 1. Cancer Lett. 2007, 246, 300-307. [CrossRef]

6. Newman, D.J.; Cragg, G.M. Natural Products as Sources of New Drugs over the Nearly Four Decades from 01/1981 to 09/2019. J. Nat. Prod. 2020, 83, 770-803. [CrossRef] [PubMed]

7. Stone, R. Biochemistry. Lifting the veil on traditional Chinese medicine. Science 2008, 319, 709-710. [CrossRef]

8. He, L.; Fan, T.; Hu, J.; Zhang, L. Polyethylene glycol-based ultrasound-assisted extraction of magnolol and honokiol from Cortex Magnoliae Officinalis. Nat. Prod. Res. 2015, 29, 31-36. [CrossRef]

9. Shen, P.; Zhang, Z.; He, Y.; Gu, C.; Zhu, K.; Li, S.; Li, Y.; Lu, X.; Liu, J.; Zhang, N.; et al. Magnolol treatment attenuates dextran sulphate sodium-induced murine experimental colitis by regulating inflammation and mucosal damage. Life Sci. 2018, 196, 69-76. [CrossRef]

10. Huang, S.Y.; Tai, S.H.; Chang, C.C.; Tu, Y.F.; Chang, C.H.; Lee, E.J. Magnolol protects against ischemic-reperfusion brain damage following oxygen-glucose deprivation and transient focal cerebral ischemia. Int. J. Mol. Med. 2018, 41, 2252-2262. [CrossRef]

11. Liu, S.; Zhou, Y.; Niu, X.; Wang, T.; Li, J.; Liu, Z.; Wang, J.; Tang, S.; Wang, Y.; Deng, X. Magnolol restores the activity of meropenem against NDM-1-producing Escherichia coli by inhibiting the activity of metallo-beta-lactamase. Cell Death Discov. 2018, 4, 28. [CrossRef]

12. Amorati, R.; Zotova, J.; Baschieri, A.; Valgimigli, L. Antioxidant Activity of Magnolol and Honokiol: Kinetic and Mechanistic Investigations of Their Reaction with Peroxyl Radicals. J. Org. Chem. 2015, 80, 10651-10659. [CrossRef]

13. Ranaware, A.M.; Banik, K.; Deshpande, V.; Padmavathi, G.; Roy, N.K.; Sethi, G.; Fan, L.; Kumar, A.P.; Kunnumakkara, A.B. Magnolol: A Neolignan from the Magnolia Family for the Prevention and Treatment of Cancer. Int. J. Mol. Sci. 2018, 19, 2362. [CrossRef]

14. Kang, Y.J.; Park, H.J.; Chung, H.J.; Min, H.Y.; Park, E.J.; Lee, M.A.; Shin, Y.; Lee, S.K. Wnt/ $\beta$-catenin signaling mediates the antitumor activity of magnolol in colorectal cancer cells. Mol. Pharmacol. 2012, 82, 168-177. [CrossRef] 
15. Lee, S.J.; Park, S.S.; Lee, U.S.; Kim, W.J.; Moon, S.K. Signaling pathway for TNF-alpha-induced MMP-9 expression: Mediation through p38 MAP kinase, and inhibition by anti-cancer molecule magnolol in human urinary bladder cancer 5637 cells. Int. Immunopharmacol. 2008, 8, 1821-1826. [CrossRef]

16. Kim, G.D.; Oh, J.; Park, H.J.; Bae, K.; Lee, S.K. Magnolol inhibits angiogenesis by regulating ROS-mediated apoptosis and the $\mathrm{PI} 3 \mathrm{~K} / \mathrm{AKT} / \mathrm{mTOR}$ signaling pathway in mES/EB-derived endothelial-like cells. Int. J. Oncol. 2013, 43, 600-610. [CrossRef]

17. Morshedloo, M.R.; Quassinti, L.; Bramucci, M.; Lupidi, G.; Maggi, F. Chemical composition, antioxidant activity and cytotoxicity on tumour cells of the essential oil from flowers of Magnolia grandiflora cultivated in Iran. Nat. Prod. Res. 2017, 31, 2857-2864. [CrossRef]

18. Zhao, M.; Zheng, Y.H.; Zhao, Q.Y.; Zheng, W.; Yang, J.H.; Pei, H.Y.; Liu, L.; Liu, K.J.; Xue, L.L.; Deng, D.X.; et al. Synthesis and evaluation of new compounds bearing 3-(4-aminopiperidin-1-yl)methyl magnolol scaffold as anticancer agents for the treatment of non-small cell lung cancer via targeting autophagy. Eur. J. Med. Chem. 2021, 209, 112922. [CrossRef]

19. Xu, T.; Zheng, Z.; Guo, Y.; Bai, L.P. Semisynthesis of novel magnolol-based Mannich base derivatives that suppress cancer cells via inducing autophagy. Eur. J. Med. Chem. 2020, 205, 112663. [CrossRef]

20. Ren, C.; Wang, J.; Tan, Y.; Guo, M.; Guo, J.; Liu, Y.; Wu, X.; Feng, Y. Synthesis, Characterization and Biological Evaluation of Magnolol and Honokiol Derivatives with 1,3,5-Triazine of Metformin Cyclization. Molecules 2020, 25, 5779. [CrossRef]

21. Tang, H.; Zhang, Y.; Li, D.; Fu, S.; Tang, M.; Wan, L.; Chen, K.; Liu, Z.; Xue, L.; Peng, A.; et al. Discovery and synthesis of novel magnolol derivatives with potent anticancer activity in non-small cell lung cancer. Eur. J. Med. Chem. 2018, 156, 190-205. [CrossRef]

22. Amblard, F.; Govindarajan, B.; Lefkove, B.; Rapp, K.L.; Detorio, M.; Arbiser, J.L.; Schinazi, R.F. Synthesis, cytotoxicity, and antiviral activities of new neolignans related to honokiol and magnolol. Bioorg. Med. Chem. Lett. 2007, 17, 4428-4431. [CrossRef] [PubMed]

23. Zhu, M.; Li, B.; Ma, H.; Huang, X.; Wang, H.; Dai, Y.; Li, Y.; Li, H.M.; Wu, C.Z. Synthesis and in vitro antitumor evaluation of honokiol derivatives. Bioorg. Med. Chem. Lett. 2020, 30, 126849. [CrossRef]

24. Singh, T.; Katiyar, S.K. Honokiol inhibits non-small cell lung cancer cell migration by targeting $P G E_{2}$-mediated activation of $\beta$-catenin signaling. PLOS ONE 2013, 8, e60749. [CrossRef]

25. Lee, H.J.; Seo, N.J.; Jeong, S.J.; Park, Y.; Jung, D.B.; Koh, W.; Lee, H.J.; Lee, E.O.; Ahn, K.S.; Ahn, K.S.; et al. Oral administration of penta-O-galloyl- $\beta$-D-glucose suppresses triple-negative breast cancer xenograft growth and metastasis in strong association with JAK1-STAT3 inhibition. Carcinogenesis 2011, 32, 804-811. [CrossRef] [PubMed]

26. Jang, S.Y.; Lee, J.K.; Jang, E.H.; Jeong, S.Y.; Kim, J.H. Shikonin blocks migration and invasion of human breast cancer cells through inhibition of matrix metalloproteinase-9 activation. Oncol. Rep. 2014, 31, 2827-2833. [CrossRef]

27. Shahi Thakuri, P.; Gupta, M.; Singh, S.; Joshi, R.; Glasgow, E.; Lekan, A.; Agarwal, S.; Luker, G.D.; Tavana, H. Phytochemicals inhibit migration of triple negative breast cancer cells by targeting kinase signaling. BMC Cancer 2020, 20, 4. [CrossRef] [PubMed]

28. Semenza, G.L. HIF-1 and tumor progression: Pathophysiology and therapeutics. Trends Mol. Med. 2002, 8, S62-S67. [CrossRef]

29. Xu, Q.H.; Xiao, Y.; Li, X.Q.; Fan, L.; Zhou, C.C.; Cheng, L.; Jiang, Z.D.; Wang, G.H. Resveratrol Counteracts Hypoxia-Induced Gastric Cancer Invasion and EMT through Hedgehog Pathway Suppression. Anticancer Agents Med. Chem. 2020, 20, 1105-1114. [CrossRef]

30. Nagaraju, G.P.; Bramhachari, P.V.; Raghu, G.; El-Rayes, B.F. Hypoxia inducible factor-1 $\alpha$ : Its role in colorectal carcinogenesis and metastasis. Cancer Lett. 2015, 366, 11-18. [CrossRef]

31. Al-Ostoot, F.H.; Sherapura, A.; Vigneshwaran, V.; Basappa, G.; Vivek, H.K.; Prabhakar, B.T.; Khanum, S.A. Targeting HIF-1 $\alpha$ by newly synthesized Indolephenoxyacetamide (IPA) analogs to induce anti-angiogenesis-mediated solid tumor suppression. Pharmacol. Rep. 2021. [CrossRef] [PubMed]

32. Choi, J.Y.; Jang, Y.S.; Min, S.Y.; Song, J.Y. Overexpression of MMP-9 and HIF-1 $\alpha$ in Breast Cancer Cells under Hypoxic Conditions. J. Breast Cancer 2011, 14, 88-95. [CrossRef]

33. Shah, P.; Westwell, A.D. The role of fluorine in medicinal chemistry. J. Enzym. Inhib. Med. Chem. 2007, 22, 527-540. [CrossRef] [PubMed]

34. Ojima, I. Use of fluorine in the medicinal chemistry and chemical biology of bioactive compounds-A case study on fluorinated taxane anticancer agents. ChemBioChem 2004, 5, 628-635. [CrossRef]

35. Hagmann, W.K. The many roles for fluorine in medicinal chemistry. J. Med. Chem. 2008, 51, 4359-4369. [CrossRef] [PubMed] 